\title{
COMPARATIVE STUDY OF EFFICACY OF PLATELET RICH PLASMA VERSUS MINOXIDIL (5\%-10\%) IN THE TREATMENT OF ANDROGENETIC ALOPECIA IN MALES
}

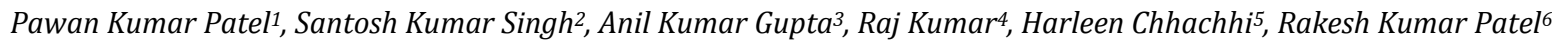 \\ $13^{\text {rd }}$ Year Junior Resident, Department of Skin, VD \& Leprosy, B.R.D. Medical College, Gorakhpur, Uttar Pradesh. \\ ${ }^{2}$ Associate Professor, Department of Skin, VD \& Leprosy, B.R.D. Medical College, Gorakhpur, Uttar Pradesh. \\ ${ }^{3}$ Associate Professor, Department of Skin, VD \& Leprosy, B.R.D. Medical College, Gorakhpur, Uttar Pradesh. \\ ${ }^{4} 3^{\text {rd }}$ Year Junior Resident, Department of Skin, VD \& Leprosy, B.R.D. Medical College, Gorakhpur, Uttar Pradesh. \\ ${ }^{5} 3^{\text {rd }}$ Year Junior Resident, Department of Skin, VD \& Leprosy, B.R.D. Medical College, Gorakhpur, Uttar Pradesh. \\ ${ }^{6} 3^{\text {rd }}$ Year Junior Resident, Department of Skin, VD \& Leprosy, B.R.D. Medical College, Gorakhpur, Uttar Pradesh.
}

\section{ABSTRACT}

AIM

To compare the efficacy of platelet rich plasma versus minoxidil (5\%-10\%) in the treatment of androgenetic alopecia in males.

\section{MATERIAL AND METHODS}

Two hundred and twenty male patients of age group 20-50 year, clinically diagnosed as androgenetic alopecia of grade II to VII (Norwood-Hamilton Classification) were included in the study and randomly divided in two groups. First group was treated by platelet rich plasma and second group was treated by Minoxidil. Response was assessed till 6 months followed by every 15 days visit, on the basis of investigator assessment and photographic assessment.

\section{STATISTICAL METHODS}

Fisher test and Chi-square test.

\section{RESULTS}

Good response was seen in $76 \%$ cases with the platelet rich plasma and $48 \%$ with minoxidil.

\section{CONCLUSION}

Platelet rich plasma can be an effective form of treatment in androgenetic alopecia than minoxidil.

\section{KEYWORDS}

Platelet Rich Plasma (PRP), Minoxidil, Fisher Test, Chi-Square Test.

HOW TO CITE THIS ARTICLE: Patel PK, Singh SK, Gupta AK, et al. Comparative study of efficacy of platelet rich plasma versus minoxidil (5\%-10\%) in the treatment of androgenetic alopecia in males. J Evolution Med Dent Sci 2016;5(2):131-134 DOI: $10.14260 /$ jemds/2016/32

\section{INTRODUCTION \\ Androgenetic Alopecia (AGA) in males is progressive patterned hair loss in which there occurs androgen mediated conversion of susceptible terminal hairs into vellus hairs in genetically predisposed individuals.[1] The prevalence and severity of male baldness increases with age. By the age of 20 over $90 \%$ of men demonstrate some degree of AGA. The main effect of AGA is psychological.[1] Conventional therapies for AGA may not be always effective, require life-long compliance and are associated with unacceptable side effect of sexual dysfunction. Hair restoration surgery is also a very tedious procedure. Platelet Rich Plasma (PRP) is being widely used in a number of medical and surgical specialities to enhance tissue repair and healing. Its potentiality to promote hair growth in areas containing hair follicles is known since 1900.[2]}

Financial or Other, Competing Interest: None.

Submission 16-12-2015, Peer Review 17-12-2015,

Acceptance 01-01-2016, Published 06-01-2016.

Corresponding Author:

Dr. Pawan Kumar Patel,

Room No. 49, Old PG Hostel,

Department of Skin \& VD

BRD Medical College,

Gorakhpur-273013,

Uttar Pradesh.

E-mail: pawankumarpatel07@gmail.com

DOI:10.14260/jemds/2016/32
Considering the early clinical evidence and basic science that supports the application of PRP in hair restoration surgery, it is reasonable to evaluate PRP for treatment of androgenetic alopecia. PRP, an autologous concentration of human platelets in a small volume of plasma has a higher platelet concentration (4-7 times) above the baseline. It is obtained from the patient's own blood after processing in an automated centrifuge and it is injected subcutaneously into the area of alopecia.[3] Hence, method of Promoting hair growth by application of a blood extract is an interesting and upcoming safe, easy and inexpensive modality to treat AGA, with no danger of allergic reactions. We undertook this study to compare the two treatment modalities of androgenetic alopecia i.e. platelet rich plasma and minoxidil.

\section{MATERIAL AND METHODS}

This was a comparative study where in 220 male patients of androgenetic alopecia were taken, in which 110 patients were randomly selected for PRP and other 110 for minoxidil over a period of 6 months.

The 220 patients of androgenetic alopecia were randomized based on simple random sampling method. Only cases of androgenetic alopecia of grade II to VII with age group 20 to 50 year were included in the study. The effect was compared to the baseline after 3 months of post treatment. 
No blinding was done in the study. Sample size determination was done as follows

Where $\mathrm{n}=$ Sample size

$$
\mathrm{n}=\frac{4 \mathrm{P} \times \mathrm{q}}{\mathrm{d}^{2}}
$$

$\mathrm{p}=$ prevalence $(50 \%)$

$\mathrm{q}=1-\mathrm{p}$

$\mathrm{d}=$ Allowable error $(10 \%)$

$\mathrm{n}=\frac{4 \times 0.5 \times 0.5}{0.1 \times 0.1}=100$

Applying design effect of 2 , the sample size comes out to be $100 \times 2=200$.

Assuming $10 \%$ patients lost follow up. So final sample size will be 220 .

Written consent will be taken from all those patients who approached for the study in Hindi/English after explaining them the procedure \& purpose of study. Selected patients will be thoroughly examined for type of hair (Terminal or vellus hair, density, calibre, i.e. coarse or fine, colour), degree and pattern of hair loss. Base line investigations such as Complete Blood Count, ESR, Serum Iron/Ferritin, Thyroid Profile, Bleeding Time and Clotting Time, Random Blood Sugar, ELISA for HIV I and II.

\section{METHOD TO PREPARE PRP}

Collect $10-20 \mathrm{ml}$ of patient's blood and mix it with anticoagulant such as Acid Citrate Dextrose (ACD). Platelet Rich Plasma prepared by two stage of centrifugation process. After centrifugation, the platelets and other growth factors raise at the top of tube. Before injecting Platelet Rich Plasma, it is activated by mixing calcium gluconate $(1$ part calcium gluconate and 9 parts of PRP) as an activator. [4] Under the topical anaesthesia, activated and highly concentrated platelet rich plasma injected into the scalp with the help of insulin syringe.

A total of 6 such sittings will be given to each patient at interval of 15 days each, over a total period of 3 months. Also, for patient satisfaction, placebo in the form of hair oil, a nonmedicated shampoo and capsule B-complex will be given for rest of the days during the course of therapy. Patients will be instructed not to alter their hair style or dye their hair during the study period.

Measurement of hair density and diameter (thickness) will be done by investigators clinical assessment and by the photographs. Photographs will be taken before the procedure and then periodically every 15 days for the first 3 months, and then monthly for another 3 months. Data will be collected and analysed by appropriate statistical method.

\begin{tabular}{|c|c|c|}
\hline $\begin{array}{c}\text { Age Group } \\
\text { (Years) }\end{array}$ & No. of Patients & \% of Patients \\
\hline $20-30$ & 81 & $74 \%$ \\
\hline $31-40$ & 23 & $21 \%$ \\
\hline $41-50$ & 06 & $5 \%$ \\
\hline Total & $\mathbf{1 1 0}$ & $\mathbf{1 0 0 \%}$ \\
\hline \multicolumn{3}{|c|}{ Table 1: PRP Group } \\
\hline
\end{tabular}

\section{RESULTS}

A total of 220 male patients were enrolled in the study. In the PRP group 110 patients were enrolled and other 110 patients were enrolled in minoxidil group.
Among the PRP study groups, total number of patients is $110(100 \%)$ which include 81 (74\%) patients of age group 20 30 year, $23(21 \%)$ patients of age group and $6(5 \%)$ patients of age group 41-50.

Among the minoxidil study groups, total number of patients is $110(100 \%)$ which include $77(70 \%)$ patients of age group 20-30 year, 24 (22\%) patients of age group and $9(8 \%)$ patients of age group 41-50.

\section{Post-Procedure Evaluation}

After 3 months of procedure, response was calculated for both the groups and the same has been depicted in Table 3 . The various hair growth parameters measured after 3 months of the first treatment were compared with the baseline study before treatment. The results of this study showed a significant increase in the mean hair count for the treatment area after three months ( 3 months versus 0 month) with significant increase of hairs in the target area compared to baseline In addition, terminal hair density improved significantly in the treatment area compared to baseline.

\begin{tabular}{|c|c|c|}
\hline $\begin{array}{c}\text { Age Group } \\
\text { (years) }\end{array}$ & No. of Patients & \% of Patients \\
\hline $20-30$ & 77 & $70 \%$ \\
\hline $31-40$ & 24 & $22 \%$ \\
\hline $41-50$ & 9 & $8 \%$ \\
\hline Total & $\mathbf{1 1 0}$ & $\mathbf{1 0 0 \%}$ \\
\hline \multicolumn{3}{|c|}{ Table 2: Minoxidil Group } \\
\hline
\end{tabular}

\begin{tabular}{|c|c|c|c|}
\hline Regrowth of hair & PRP & Minoxidil & P-value \\
\hline Good & 76 & 48 & \\
Fair & 23 & 39 & $\mathrm{P}=0.000647$ \\
Poor & 11 & 23 & \\
Total & $\mathbf{1 1 0}$ & $\mathbf{1 1 0}$ & \\
\hline \multicolumn{4}{|c|}{ Table 3 } \\
\hline
\end{tabular}

In the PRP method, 76 (91.20\%) patients showed good response [Figs. 1 and 2], 23 (20.9\%) patients showed fair response [Figs. 3 and 4], 11 (10\%) patients showed poor response. [Figs. 5 and 6 ].

\section{Good Response of PRP}

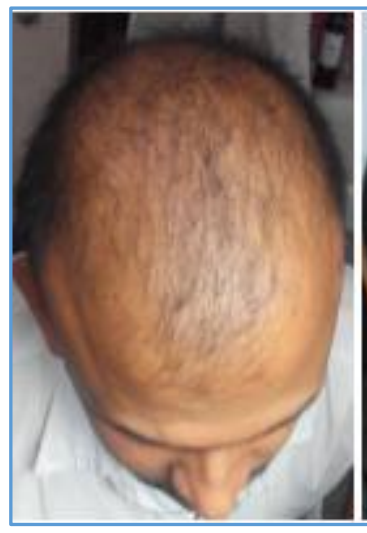

Fig.1

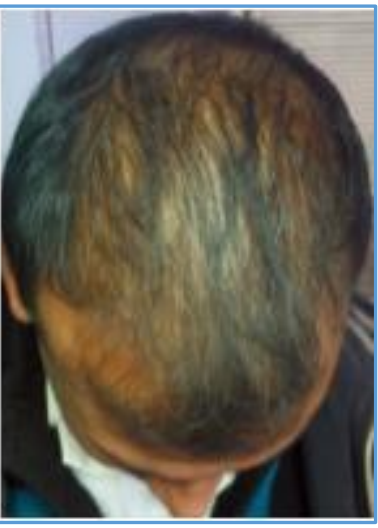

Fig. 2 


\section{Good Response of Minoxidil}

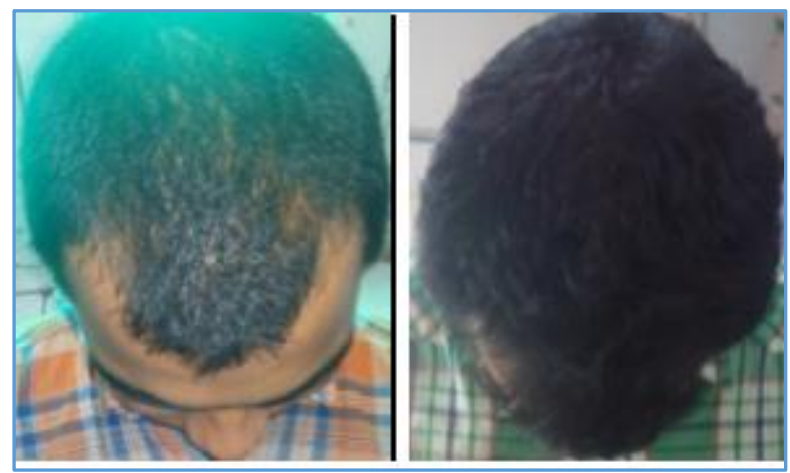

Fig. 5

Fig. 6

\section{Fair Response of PRP}

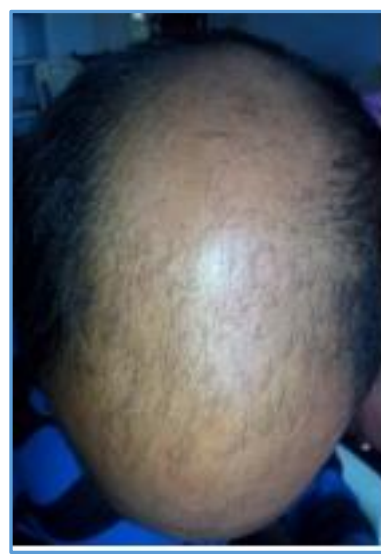

Fig. 3

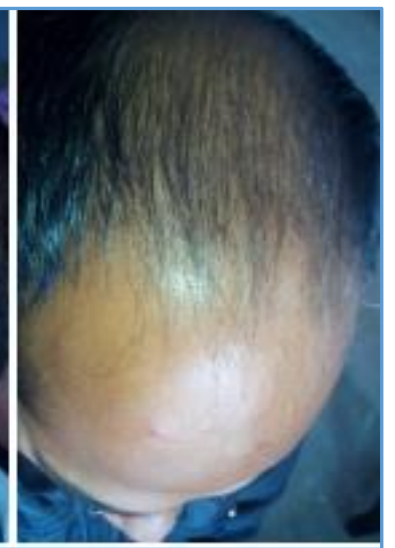

Fig. 4

\section{Fair Response of Minoxidil}

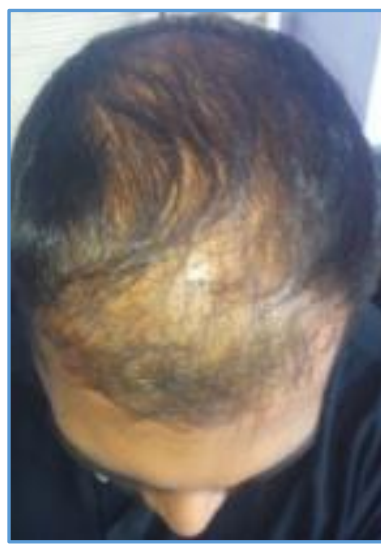

Fig. 7

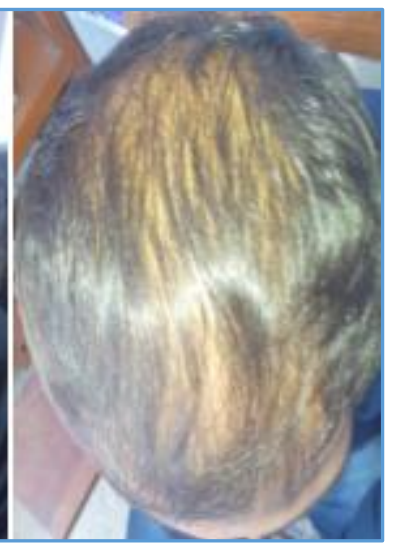

Fig. 8
By using Chi-square test $\mathrm{p}$-value for hair regrowth noted after 3 months was 0.000647 , which was $<0.05$; therefore there was positive statistical association between treatment methodology and hair regrowth.

By PRP methods, hair regrowth is good in young patients, i.e. 20 to 30 years and in those patients having history of lesser duration of hair fall. Patients having prolong history of hairfall or older age group show poor response. However, the effect of minoxidil is slow and also its take time.

\section{DISCUSSION}

Androgenetic Alopecia (AGA), a hereditary and androgendependent progressive thinning of the scalp hair in a defined pattern, is a common dermatological disorder affecting more in men and occasionally in women, with significant negative impact on their social and psychological wellbeing. It commonly begins by 20 years of age and affects nearly $50 \%$ of men by the age of 50 years. [5] Its etiopathogenesis is mainly androgen-dependent and modulated via the testosterone metabolite dihydrotestosterone, the expression of hair folliclerelated androgen receptor; and genetic factors also have been implicated.[6]

Since androgenetic alopecia is characterised by a shortened anagen phase and miniaturization of terminal to vellus hair.[5] current therapeutic strategies target cellular proliferation and differentiation during the hair cycle.

Current strategies for the treatment of pattern hair loss are mainly focused on promoting cellular proliferation and differentiation during the hair growth cycle. FDA-approved drug therapies include finasteride and minoxidil.[7,8,9] Minoxidil appears to prolong anagen phase and to promote survival of dermal papilla cells and increase in hair follicle size.[10,11] Oral finasteride also induces the prolongation of anagen hairs, which results in gradual thickening and elongation of the hairs.[12]

PRP, an autologous concentration of human platelets in a small volume of plasma has a higher platelet concentration (4-7 times) above the baseline. It is obtained from the patient's own blood after processing in an automated centrifuge and it is injected subcutaneously into the area of alopecia.[13] Activated PRP increased the proliferation of dermal papilla (DP) cells and stimulated extracellular signal regulated kinase and AKT signaling. Fibroblast growth factors 7 (FGF-7) and beta-catenin, both potent stimuli of hair growth, where up regulated in the DP cells. Activated PRP promotes the proliferation of dermal papillary cells and prevents their apoptosis.

PRP induced activation of anti-apoptotic regulators and prolongs the survival of dermal papilla cells during the hair cycle.[14,15] In addition, PRP treatment is suggested to stimulate hair growth by inducing follicular stem cell differentiation as well as prolonging the anagen phase of the hair growth cycle.[14,16] It also appears to increase the peri-follicular vascular plexus, through the increase of VEGF and PDGF levels, which have an angiogenic potential. Therefore, it constitutes a potent useful tool for androgenetic alopecia treatment.

The main growth factors involved in the establishment of hair follicle are Vascular Endothelial Growth Factor (VEGF), Epidermal Growth Factor (EGF), insulin 1-like growth factor, and Fibroblast Growth Factor (FGF). Platelets release large amounts of platelet-derived growth factor (PDGFaa, PDGFbb, and PDGFab), transforming growth factor beta (TGF $\beta 1$ and ß2), EGF, and VEGF.[17]

Patients with grade II-III alopecia according to the Norwood-Hamilton scale had better results compared to patients with more advanced alopecia. Furthermore, patients with vellus hair had better results compared to those who had few but normal hair, as PRP appeared to act on hair diameter causing thin hair to become thicker. Apart from these, hair evaluation methods were not objective. Hair pull test was performed in a standardised manner by the two evaluators, but it remains a subjective evaluation method. 
Macroscopic photographs showed an overall image of hair growth and hair density. In our study, the hair pull test became negative after four sessions of PRP. This study also observed significant improvement in hair volume and coverage in global pictures.

\section{CONCLUSION}

Platelet-Rich Plasma (PRP) has emerged as a new treatment modality in regenerative plastic surgery, dermatology and aesthetics and preliminary evidence suggests that it might have a beneficial role in hair regrowth. The data clearly highlight the positive effects of PRP injections on male pattern hair loss and absence of major side effects. PRP may serve as a safe, cheap, non-allergic and effective treatment option against hair loss.

\section{REFERENCES}

1. Sinclair RD. Disorders of Hair. In: Burns T, Breathnach S, Cox N, Griffiths C, editors. Rook's Textbook of Dermatology. $8^{\text {th }}$ edition. UK: Blackwell Publishing Ltd; 2010;66.16-66.31.

2. Knighton DR, Hudson, Wis, inventors. Regents of the University of Minnesota, Minneapolis, Minn, Curative Technologies. Method for promoting hair growth. 1990 (September 18). US Patent 4957742.

3. Marx RE. Platelet-Rich Plasma (PRP): What is PRP and what is not PRP? Implant Dent. 2001;10:225-8.

4. Sunitha Raja V, Munirathnam Naidu E. Platelet-rich fibrin: Evolution of a second-generation platelet concentrate. Indian J Dent Res 2008;19:42-6.

5. Ellis JA, Sinclair R, Harrap SB. Androgenetic alopecia: Pathogenesis and potential for therapy. Expert Rev Mol Med. 2002;4:1-11. [PubMed].

6. Trüeb RM. Molecular mechanisms of androgenetic alopecia. Exp Gerontol. 2002;37:981-90. [PubMed].

7. McElwee KJ, Shapiro JS. Promising therapies for treating and/or preventing androgenic alopecia. Skin Therapy Lett. 2012;17:1-4. [PubMed].
8. Blumeyer A, Tosti A, Messenger A, Reygagne P, Del Marmol V, Spuls PI, et al. European Dermatology Forum (EDF). Evidence-based (S3) guideline for the treatment of androgenetic alopecia in women and in men. J Dtsch Dermatol Ges. 2011;9(Suppl 6):S1-57. [PubMed].

9. Jandali S, Low DW. From surgery to pharmacology to gene therapy: The past, present and future of hair restoration. Ann Plast Surg. 2010;65:437-42. [PubMed].

10. Semalty M, Semalty A, Joshi GP, et al. Hair growth and rejuvenation: An overview. J Dermatolog Treat. 2011;22:123-32. [PubMed].

11. Han JH, Kwon OS, Chung JH, Cho KH, Eun HC, Kim KH. Effect of minoxidil on proliferation and apoptosis in dermal papilla cells of human hair follicle. J Dermatol Sci. 2004;34:91-8. [PubMed].

12. Tosti A, Piraccini BM. Finasteride and the hair cycle. Journal of the American Academy of Dermatology. 2000;42(5):848-849. [PubMed].

13. Marx RE. Platelet-Rich Plasma (PRP): What is PRP and what is not PRP? Implant Dent. 2001;10:225-8. [PubMed].

14. Li ZJ, Choi H-I, Choi D-K, et al. Autologous platelet-rich plasma: a potential therapeutic tool for promoting hair growth. Dermatologic Surgery. 2012;38(7, part 11):1040-1046. [PubMed].

15. Kwon OS, Pyo HK, Oh YJ, et al. Promotive effect of minoxidil combined with all-trans retinoic acid (tretinoin) on human hair growth in vitro. Journal of Korean Medical Science. 2007;22(2):283-289. [PMC free article] [PubMed].

16. Sohn K-C, Shi G, Jang S, et al. Pitx2, a $\beta$-catenin-regulated transcription factor, regulates the differentiation of outer root sheath cells cultured in vitro. Journal of Dermatological Science. 2009;54(1):6-11. [PubMed].

17. Parsley WM, Perez-Meza D. Review of factors affecting the growth and survival of follicular grafts. J Cutan Aesthet Surg. 2010;3:69-75. [PMC free article] [PubMed]. 